\title{
Changes in nailfold videocapillaroscopy in patients with granulomatosis with polyangiitis (Wegener's): an observational study
}

\author{
Julia Uceda*, Rosalía Martinez, María L Velloso, José L Marenco \\ From 7th European Workshop on Immune-Mediated Inflammatory Diseases \\ Noordwijk aan Zee, the Netherlands. 28-30 November 2012
}

\section{Background}

Nailfold videocapillaroscopy (NFC), allows for the detection of changes in microcirculation. In the granulomatosis with polyangiitis (GPA) the existence of a defined pattern has not been found.

\section{Objectives}

The main objective of our study was to detect the possible existence of a defined pattern in the microcirculation of the nailfold capillaries of patients with GPA. The second objective was to investigate the possible correlation between abnormalities found and systemic involvement.

\section{Methods}

We identified 10 patients with a current mean age of $55.7 \pm 16.5$ years and predominantly female $(60 \%)$. The mean age at diagnosis was 49.4 years. $70 \%$ had upper respiratory tract involvement, the same percentage had pulmonary involvement (cavitated nodules or alveolar hemorrhage), the cutaneous manifestations such as purpura or necrotic ulcers were present in $70 \%$. About $40 \%$ had renal involvement (renal failure, proliferative glomerulonephritis), and $40 \%$ had peripheral neurological involvement. NFC was carried out by the same rheumatologist, on fingers 3 through to 5 of both hands using a ZUZI videocapillaroscopy, trinocular, dual illumination and zoom of $1 \mathrm{X} 4 \mathrm{X}$.

\section{Results}

Abnormalities of the microcirculation of nailfold capillaries were found in 8 of the 10 patients. Among the patients with this pathological microcirculation, $62.5 \%$ had structural alterations (tortuous capillaries), 50\% presented with micro-hemorrhage (single or multiple), avascular areas were found in $37.5 \%$ and $75 \%$ showed lower capillary density. Neither capillary dilation nor the formation of new vessels were detected within the sample of patients. Next table correlates capilaroscopic finding with organ involvement.

\section{Conclusions}

We have observed, more frequent bleeding, avascular areas and reduced capillary density and these findings were not related with any specific organ involvement. There is one only study in GPA which communicates a high percentage of avascular areas.

\section{Published: 28 November 2012}

\section{Reference}

1. Anders HJ, Haedecke C, Sigl T, Krüger K: Avascular areas on nailfold capillary microscopy of Patients with Wegeners granulomatosis. Clin Rheumatol 2000, 19(2):86-8.

doi:10.1186/1479-5876-10-S3-P29

Cite this article as: Uceda et al:: Changes in nailfold videocapillaroscopy in patients with granulomatosis with polyangiitis (Wegener's): an observational study. Journal of Translational Medicine 2012 10(Suppl 3): P29.

Rheumatology Dept., Valme University Hospital, Sevilla, Spain

(c) 2012 Uceda et al; licensee BioMed Central Ltd. This is an Open Access article distributed under the terms of the Creative Commons 